\title{
Care Transitions of Colorectal Cancer Patients from Hospital to Community: Systematic Review and Meta-analysis Protocol
}

Transiciones de cuidados de pacientes con cáncer colorrectal del hospital a la comunidad: protocolo de revisión sistemática y metaanálisis

Transição do cuidado de pacientes com câncer colorretal do hospital para a comunidade: protocolo de revisão sistemática e meta-análise

How to cite this article:

Boell, Julia Estela Willrich; Trindade, Letícia Flores; Kolankiewicz, Adriane Cristina Bernat; Cañon-Montañez, Wilson; Pituskin, Edith; Lorenzini, Elisiane. Care Transitions of Colorectal Cancer Patients from Hospital to Community: Systematic Review and Meta-analysis Protocol. 2021;12(3):e2285. http://dx.doi.org/10.15649/cuidarte.2285

\section{Revista Cuidarte}

Rev Cuid. Sep - Dic 2021; 12(3): e2285 doij http://dx.doi.org/10.15649/cuidarte.2285

\section{E-ISSN: 2346-3414}

\author{
(D) Julia Estela Willrich Boell ${ }^{1}$ \\ (1) Letícia Flores Trindade ${ }^{2}$ \\ (1D) Adriane Cristina Bernat Kolankiewicz \\ (D) Wilson Cañon-Montañez ${ }^{4}$ \\ (D) Edith Pituskin ${ }^{5}$ \\ (D) Elisiane Lorenzini ${ }^{6}$
}

1 RN, PhD. Federal University of Santa Catarina, Florianópolis, SC, Brazil.

E-mail: juliasuporte@gmail.com

2 RN, MN. Regional University of the Northwest of the State of Rio Grande do Sul, ljuí, Rio Grande do Sul, Brazil. E-mail:

leti.ftrindade@yahoo.com.br

3 RN. PhD. Regional University of the Northwest of the State of Rio Grande do Sul, Ijuí, Rio Grande do Sul, Brazil. E-mail: adriane.bernat@unijui.edu.br

4 RN. PhD. Faculty of Nursing, Universidad de Antioquia, Medellín, Antioquia, Colombia. E-mail: wilson.canon@udea.edu.co

5 RN, MN, PhD. Faculty of Nursing University of Alberta, Edmonton, Alberta, Canada.

E-mail: pituskin@ualberta.ca

6 RN. PhD. Federal University of Santa Catarina, Florianópolis, Santa Catarina, Brazil.

E-mail: elisiane.lorenzini@ufsc.br

\section{Abstract}

Objective: To evaluate the effectiveness of care transition strategies from hospital-to-community compared to usual care for patients with colorectal cancer to reduce hospital stay, 30-day readmissions, and emergency room visits up to 30 days. Methods: Systematic review and meta-analysis protocol that followed the recommendations of the Preferred Reporting Items for Systematic Reviews and Meta-Analyses Protocols (PRISMA-P). The protocol was registered on PROSPERO (CRD42020162249). We will include studies available in the electronic databases PubMed/Medline, Embase, Cochrane CENTRAL and LILACS with care transition strategies/actions from hospital to community as the primary outcome. Eligiblestudieswill be selected, and data will be combined and synthesized using Review Manager (RevMan 5.4) software. We will combine risk ratios or odds ratios for dichotomous data and mean differences for continuous data using a random effects model. Discussion: This review will contribute to the practice and development of effective and safe care transition strategies from hospital to community for colorectal cancer patients. There is an expectation that this review will provide much needed evidence that effective care transitions could reduce short term hospital readmission, and may thus provide added value in the care of colorectal cancer patients. Conclusion: The results of the review will be used to provide clear recommendations for hospital and primary care management to improve care transitions and, as a result, also improve integration in the healthcare system.

Keywords: Colorectal neoplasms, Patient transfer, Patient readmission, Systematic review, Meta-analysis.

Received: June 15th, 2021

Accepted: July 26th, 2021

Published: August $20^{\text {th }}, 2021$ $\square *$ Correspondence

Adriane Cristina Bernat Kolankiewicz

E-mail:adriane.bernat@unijui.edu.br 


\section{Transiciones de cuidados de pacientes con cáncer colorrectal del hospital a la comunidad: protocolo de revisión sistemática y metaanálisis}

\section{Resumen}

Objetivo: Evaluar la efectividad de estrategias de transición de cuidados del hospital a la comunidad en comparación con el cuidado usual en pacientes con cáncer colorrectal para reducir el tiempo de estancia hospitalaria, readmisiones a los 30 días y visitas al departamento de emergencias dentro de los 30 días. Métodos: Protocolo de revisión sistemática y metaanálisis que siguió las recomendaciones de Preferred Reporting Items for Systematic Reviews and Meta-Analyses Protocols (PRISMA-P). El protocolo se registró en PROSPERO (CRD42020162249). Se incluirán estudios disponibles en las bases de datos electrónicas PubMed/Medline, Embase, Cochrane CENTRAL y LILACS con estrategias/acciones de transición del cuidado del hospital a la comunidad como desenlace principal. Se seleccionarán los estudios elegibles y los datos se combinarán y sintetizarán mediante el software Review Manager (RevMan 5.4). Serán combinados los riesgos relativos u odds ratios para los datos dicotómicos y las diferencias de medias para los datos continuos mediante un modelo de efectos aleatorios. Discusión: Esta revisión contribuirá a la práctica y el desarrollo de estrategias de transición de cuidado efectivas y seguras del hospital a la comunidad para los pacientes con cáncer colorrectal. Se espera que esta revisión proporcione evidencias muy necesarias de que las transiciones de cuidado efectivas podrían reducir la readmisión hospitalaria a corto plazo y, por lo tanto, pueden proporcionar un valor agregado en el cuidado de los pacientes con cáncer colorrectal. Conclusión: Los resultados de la revisión se utilizarán para proporcionar recomendaciones claras para la gestión hospitalaria y de cuidado primario para mejorar las transiciones de cuidado y, como resultado, también mejorar la integración en el sistema de salud.

Palabras clave: Neoplasias colorrectales, Transferencia de pacientes, Readmisión del paciente, Revisión sistemática, Metaanálisis.

\section{Transição do cuidado de pacientes com câncer colorretal do hospital para a comunidade: protocolo de revisão sistemática e meta-análise}

\section{Resumo}

Objetivo: Avaliar a efetividade de estratégias de transição do cuidado do hospital para a comunidade comparada aos cuidados habituais para pacientes com câncer colorretal para diminuir tempo de permanência hospitalar, readmissões aos 30 dias e visita ao setor de emergência até 30 dias. Métodos: Protocolo de revisão sistemática e meta-análise que seguiu as recomendações do Preferred Reporting Items for Systematic Reviews and Meta-Analyses Protocols (PRISMA-P). O protocolo foi registrado no PROSPERO (CRD42020162249). Incluiremos estudos disponíveis nas bases de dados eletrônicas PubMed/Medline, Embase, Cochrane CENTRAL e LILACS tendo como desfecho primário as estratégias/ações de transição do cuidado do hospital para a comunidade. Os estudos elegíveis serão selecionados e os dados serão combinados e sintetizados usando o software Review Manager (RevMan 5.4). Serão combinados os riscos relativos ou odds ratios para dados dicotômicos e diferenças de médias para dados contínuos usando um modelo de efeitos aleatórios. Discussão: Esta revisão contribuirá para a prática e desenvolvimento de estratégias de transição de cuidados efetivas e seguras do hospital para a comunidade para pacientes com câncer colorretal. Espera-se que esta revisão forneça evidências muito necessárias de que as transições de cuidados efetivas podem reduzir a readmissão hospitalar de curto prazo e podem, assim, fornecer valor agregado no cuidado de pacientes com câncer colorretal. Conclusão: Os resultados da revisão serão usados para fornecer recomendações claras para a gestão hospitalar e de cuidados primários para melhorar as transições de cuidados e, como resultado, também melhorar a integração no sistema de saúde.

Palavras-chave: Neoplasias colorretais, Transferência de pacientes, Readmissão do paciente, Revisão sistemática, Metanálise. 


\section{Introduction}

Cancer has taken on large proportions worldwide and its incidence has progressively increased, with high morbidity and mortality'. Globally, one in five men and one in six women develop cancer during their lifetime, and one in eight men and one in each 11 women die from the disease ${ }^{1}$. Worldwide, an estimated 19.3 million new cancer cases and almost 10.0 million cancer deaths occurred in $2020^{2}$. In the Americas in 2020, cancer was responsible for $20.9 \%$ of all cases worldwide and for $14.2 \%$ of mortality ${ }^{2}$. Still, regarding the types of cancers, colorectal is in third place in terms of incidence, and second in terms of mortality ${ }^{2}$. More than 1.9 million new cases of colorectal cancer (CRC) and 935,000 deaths occurred in 2020, representing about one in 10 cancer cases and deaths ${ }^{2}$.

In developing countries, such as Brazil, limitations on access to healthcare, such as low coverage of screening programs and delays in carrying out diagnostic and therapeutic procedures ${ }^{3,4}$ contribute to the increase of the incidence and mortality from this disease $\mathrm{s}^{5}$. In addition, geographical, economic and social barriers contribute to hamper access and generate worse health outcomes ${ }^{6}$. Among other weaknesses, health services operate in a fractional way in the healthcare system, which negatively affects patients and their families, who receive fragmented care ${ }^{7}$.

The increasing complexity of treatment regimens associated with the growing prevalence of chronic conditions shows the importance of coordinating healthcare services. However, there is evidence that patients with multiple chronic conditions frequently do not receive patientcentered care, despite the importance of providing care that meets patients' needs and preferences and the recognition of the role of patients and family members as part of the care team ${ }^{8,9,10}$. This highlights the needs of planning strategies, mainly at the management level, that provide access in a timely manner and that guarantee comprehensive and continuous care, which in turn directly reflects on timely access to the proposed treatment for CRC patients.

Comprehensive care for people with CRC requires a demand for long-term care in order to ensure effective and integral care aimed at solving their health problems. Due to these characteristics, it is necessary that the care for cancer patients be carried out at home by family members and / or caregivers in addition to the specialized service.

A key component of integration in healthcare is care transition (CT), which is defined as "a set of actions designed to ensure safe and effective coordination and continuity of care as clients experience a change in health status, care needs, health care providers, or location"11,12. However, care transitions continue to be poorly managed, particularly from hospital to home ${ }^{13}$. For patients with multiple, complex chronic conditions, such as CRC, CT is critical and strategies can be adopted to improve the quality in the care continuum ${ }^{14}$.

Despite the evidence of unsafe care transitions, the impact of patient safety, and a plethora of literature on care transitions, significant gaps continue in practice and policy highlighting the need for implementation research to improve care transitions from hospital to community to advance quality and safety in our health care systems. Also, it is important to highlight that care transition strategies must include patients, families, and caregivers, once these folks are involved in the treatment and care. Furthermore, these patients are frequently dependent on technology and devices for continuity of care and support resources at the time of discharge ${ }^{15}$. 
From this perspective, to follow up on the patient's care is necessary that the patient and their families are actively involved in discharge planning, as well as, their opinions be given visibility during this process ${ }^{16}$. Thus, hospital discharge is a process that must be taken seriously in the patient's care plan, with a view of facilitating their transition from the service to the home ${ }^{17}$. In addition, to become effective, it is necessary that the time of discharge become a humanized process, providing support through professional guidance on care and self-care ${ }^{18}$. Therefore, CT is characterized as a complex process that requires coordination and communication between people of different backgrounds, experiences, and skills ${ }^{19}$.

CT is currently under construction and adaptation in Brazil. There is no standardization of strategies and effective actions to improve $\mathrm{CT}$ routinely performed during the hospitalization process. Thus, it lacks investigations at the national and international ambits ${ }^{20,16}$. In summary, conducting a bibliographic survey is essential to recognize the relevance and complexity of the hospital-community transition, especially in CRC patients. Thus, considering the relevance of identifying and summarizing safe, effective and resolving $\mathrm{CT}$, this systematic review is justified.

The purpose of this systematic review and meta-analysis is to evaluate the effectiveness of transition strategies from hospital-to-community care compared to usual care for patients with colorectal cancer to reduce hospital stay and reduce readmission and/or emergency room visits within 30 days. We seek to answer the following research question: How effective are care transition strategies from hospital-to-community compared to usual care for patients with colorectal cancer to reduce hospital stay, 30-day readmissions, and emergency room visits up to 30 days?

\section{Methods}

\section{Protocol and registration}

This systematic review and meta-analysis will be conducted according to the recommendations of the Preferred Reporting Items for Systematic Reviews and Meta-Analyses Protocols (PRISMA-P) ${ }^{21}$. The protocol was registered in the International Prospective Register of Systematic Reviews (PROSPERO) under number CRD42020162249.

\section{Criteria for considering studies for the review}

\section{Types of studies}

Will be eligible for inclusion, quasi-experimental studies or non-randomized trials and randomized controlled trials. Additionally, using the Population, Intervention, Comparison and Outcome (PICO) strategy we elaborated the guiding question of this review in order to ensure the systematic search of available literature: Which care transition strategies are effective compared to the usual care for the transition of CRC patients from hospital to community? The PICO strategy is provided in Table 1. 
Table 1. Description of the PICO (population, intervention, comparator and outcome) strategy.

\begin{tabular}{ll}
\hline \multicolumn{1}{c}{ Definition } & \multicolumn{1}{c}{ Description } \\
\hline P - Population & Colorectal cancer patients \\
I - Intervention & Care transition strategies \\
C - Comparison & Usual care strategies by the hospital healthcare team \\
O - Outcome & Effective care strategies/actions from the hospital to the community \\
\hline
\end{tabular}

This protocol will follow standard systematic review methods and use a random-effects metaanalytic approach to synthesize the review findings. This review will consider 'interventions' as any specific initiatives intended to improve care transitions strategies from hospital to community for CRC patients in healthcare organisations.

\section{Types of participants}

In order to answer the research question studies must focus on strategies from the health care team developed from CRC patients.

\section{Data sources}

\section{Search strategy and data management}

The following databases will be explored for relevant studies: PubMed/Medline, Embase, Cochrane CENTRAL and Lilacs. Languages to include: English, Portuguese and Spanish. Publication period: Studies published from inception until April 31 ${ }^{\text {st }}, 2020$. In addition, we will review the reference lists of selected studies to see if there are other possible studies to be included.

The search strategy will be designed by combining keywords, MeSH terms, entry terms and using the AND/OR boolean operators. The following keywords and MeSH terms will be combined according to each investigated database: continuity of patient care, patient transfer, transitional care, patient discharge, patient readmission, care transition, transition of care, discharge planning, continuity of care, care coordination and colorectal neoplasms. This search strategy is described in Table 2.

Table 2. Search strategy for electronic databases.

\begin{tabular}{|c|c|}
\hline PubMed/Medline & Embase \\
\hline $\begin{array}{l}\text { 1. "Continuity of Patient Care"[All Fields] } \\
\text { 2. "Patient Transfer"[All Fields] } \\
\text { 3. "Transitional care"[All Fields] } \\
\text { 4. "Patient discharge"[All Fields] } \\
\text { 5. "Patient readmission"[All Fields] } \\
\text { 6. "Care transition"[All Fields] } \\
\text { 7. "Transition of care"[All Fields] } \\
\text { 8. "Continuity of care"[All Fields] } \\
\text { 9. "Care coordination"[All Fields] } \\
\text { 10. "Discharge planning"[All Fields] } \\
\text { 11. } 1 \text { OR } 2 \text { OR } 3 \text { OR } 4 \text { OR } 5 \text { OR } 6 \text { OR } 7 \text { OR } 8 \text { OR } 9 \text { OR } 10 \\
\text { 12. "Colorectal neoplasms"[All Fields] } \\
\text { 13. } 11 \text { AND } 12\end{array}$ & $\begin{array}{l}\text { 1. Continuity of patient care/exp OR continuity of patient care } \\
\text { 2. Patient transfer/exp OR patient transfer } \\
\text { 3. Transitional care/exp OR transitional care } \\
\text { 4. Patient discharge/exp OR patient discharge } \\
\text { 5. Patient readmission/exp OR patient readmission } \\
\text { 6. Care transition/exp OR care transition } \\
\text { 7. Transition of care/exp OR transition of care } \\
\text { 8. Discharge planning/exp OR discharge planning } \\
\text { 9. Continuity of care/exp OR continuity of care } \\
\text { 10. Care coordination } \\
\text { 11. } 1 \text { OR } 2 \text { OR } 3 \text { OR } 4 \text { OR } 5 \text { OR } 6 \text { OR } 7 \text { OR } 8 \text { OR } 9 \text { OR } 10 \\
\text { 12. Colorectal neoplasms'/exp OR colorectal neoplasms } \\
\text { 13. } 11 \text { AND } 12\end{array}$ \\
\hline Cochrane CENTRAL & Lilacs \\
\hline $\begin{array}{l}\text { 1. Continuity of patient care } \\
\text { 2. Patient transfer } \\
\text { 3. Transitional care } \\
\text { 4. Patient discharge } \\
\text { 5. Patient readmission } \\
\text { 6. Care transition } \\
\text { 7. Transition of care } \\
\text { 8. Discharge planning } \\
\text { 9. Continuity of care } \\
\text { 10. Care coordination } \\
\text { 11. } 1 \text { OR } 2 \text { OR } 3 \text { OR } 4 \text { OR } 5 \text { OR } 6 \text { OR } 7 \text { OR } 8 \text { OR } 9 \text { OR } 10 \\
\text { 12. Colorectal neoplasms } \\
\text { 13. } 11 \text { AND } 12\end{array}$ & $\begin{array}{l}\text { 1. "Continuity of Patient Care" OR "Patient Transfer" OR } \\
\text { "Transitional care" OR "Patient discharge" OR "Patient readmission" } \\
\text { OR "Care transition" OR "Transition of care "OR "Continuity of care" } \\
\text { OR "Care coordination" OR "Discharge planning" } \\
\text { 2. "Colorectal neoplasms" }\end{array}$ \\
\hline
\end{tabular}


Search results will be downloaded into Mendeley ${ }^{\circledR}$ data management software to identify and delete any duplicates. Full-text articles will be available for all authors.

\section{Eligibility criteria and quality assessment}

Two authors will independently review the studies, in case of uncertainty/doubt, a third author will be involved in order to reach a consensus. The selection of studies will be performed in three steps. First, the titles will be read, followed by the abstracts reading and finally, the indepth reading will be done, of the remaining studies from previous phases, in order to identify the potentially eligible ones.

To assess the levels and quality of evidence, studies will be graded as recommended by the Joanna Briggs Institute (JBI). Methodological quality will be assessed by different instruments according to the type of study. We will assess the risk of bias using the Cochrane Collaboration tool for randomized controlled trials and ROBINS-I tool for non-randomized trials studies of interventions.

\section{Data extraction and analysis}

The narrative synthesis for each result will be provided in a table of evidence by two independent authors, which are going to reach a consensus in case of divergences. The following information will be extracted: article identification (authors/ year of publication/ country of study), study design, methodological aspects, focus of interventions and outcomes. Any relevant information missing from the study will be requested from the original authors of the article, if necessary. When appropriate, data will be combined and synthesized in a meta-analysis using Review Manager (RevMan 5.4) software. We will combine risk ratios (RR) or odds ratios (OR) for dichotomous data and mean differences (MD) for continuous data using random-effects models. All data will be presented with $95 \%$ intervals of confidence. Statistical heterogeneity between studies will be assessed using the $\mathrm{I}^{2}$ statistic.

This review will consider primary outcome as effective care transition strategies/actions from hospital to community. The secondary outcome of interest will be patient safety at hospital discharge; reduction of hospital costs to the health system. For the secondary outcome we will consider results of interventions that evaluated readmissions in colorectal patient, length of stay, and emergency department (ED) visits.

\section{Risk of bias in individual studies}

Two reviewers will independently evaluate the quality of the studies. Possible disagreements will be resolved by consensus or with the consultation of third parties.

We will assess the risk of bias using the Cochrane Collaboration tool (RoB 2) for randomized controlled trials, using the following criteria or domains: bias arising from the randomization process; bias due to deviations from intended interventions; bias due to missing outcome data; bias in measurement of the outcome; bias in selection of the reported result. We will judge the risk of bias as 'low risk', 'some concerns' and 'high risk' as described in the Cochrane Handbook for Systematic Reviews of Interventions. 


\section{Ethical considerations}

This research is being conducted using meta-analysis methods with existing trial data. The analyses will not include any identifiable patient data. Ethical committee approval was not required for this research.

\section{Discussion}

Due to the lack of research on this topic in Brazil, this review will contribute to the practice and development of effective and safe care transition strategies from hospital to community for CRC patients. Therefore, development and implementation strategies during the discharge plan are essential for the safe transition of the patient from the hospital to the community ${ }^{22}$. Thus, it is important that professionals in the hospital environment develop and offer CT for CRC patients and their families, with these transition strategies and practices based on evidence, with a view to contributing to greater patient safety, improving the continuity of care and, consequently, the quality of patients' life ${ }^{23}$ and the quality of health care $\mathrm{c}^{24,25}$.

There is an expectation that this review will provide much needed evidence that effective care transitions could reduce short term hospital readmission, and may thus provide added value in the care of CRC patients.

The results of the review will be used to provide clear recommendations for hospital and primary care management to improve care transitions, and as a result, also improve integration in the healthcare system. Indeed, there is no previous research that aimed to find the most effective interventions to improve care transition in CRC patients. The key challenge is to find different interventions addressing all of the continuity of care dimensions. The outcome of this systematic review and meta-analysis will be an understanding of the evidence for the relationship between effective care transition strategies from hospital to community for CRC patients.

\section{Limitations}

Systematic reviews and meta-analyses are powerful tools that summarize the evidence for current best practice guidelines for the available interventions for a particular problem ${ }^{26,27}$. However, scientific evidence from mega trials are rarely available for most medical conditions. Therefore, some limitations can compromise the quality of the review due to the inherently risk of bias associated with the eligible studies. To minimize it we will address each risk of bias with appropriate tools as described in the method section and will critically explore the evidence to provide recommendations using JBI method.
The results of the review will be used to provide clear recommendations for hospital and primary care management to improve care transitions, and as a result, also improve integration in the healthcare system.
Therefore, development and implementation strategies during the discharge plan are
essential for the safe transition of the patient from the hospital to the community ${ }^{22}$. 


\section{Conclusion}

CRC patients require ongoing care with the need for integration and organization of care across the health system, which must include their families and/or caregivers. Thus, arrangement must be done to provide actions in health services to ensure quality and safety during the care transition. The scientific evidence from this review will contribute to identify and disseminates effective strategies for the continuity of care for patients with colorectal cancer after hospital discharge. From this perspective, future studies research could also be developed in this field and contribute for the formulation and implementation of guidelines addressed to the continuity of care for patients with CRC.

Conflict of Interest: The authors have no conflicts of interest to declare.

Acknowledgments: We thank CAPES (Coordenação de Aperfeiçoamento de Pessoal de Nível Superior - Brazil) for the postdoctoral fellowship provided to Julia Estela Willrich Boell.

Source of Funding: None.

\section{References}

1. Lin L, Yan L, Liu Y, Yuan F, Li H, Ni J. Incidence and death in 29 cancer groups in 2017 and trend analysis from 1990 to 2017 from the Global Burden of Disease Study. J Hematol Oncol 2019;12(1): 96. https://doi.org/10.1186/s13045-019-0783-9

2. Sung H, Ferlay J, Siegel RL, Laversanne M, Soerjomataram I, Jemal A, et al. Global Cancer Statistics 2020: GLOBOCAN Estimates of Incidence and Mortality Worldwide for 36 Cancers in 185 Countries. CA Cancer J Clin. 2021;71(3):209-249. https://doi.org/10.3322/caac.21660

3. Lorenzini E, Boell JEW, Oelke ND, Rodrigues CD, Trindade LF, Winter VDB, et al. Care transition from hospital to home: cancer patients' perspective. BMC Res Notes 2020;13(1):267. https://doi.org/10.1186/s13104-020-05099-x

4. Lorenzini E, Boell JEW, Oelke ND, Rodrigues C D, Trindade LF, Winter VDB, et al. Cancer patient's care transition database.xlsx. figshare. Dataset 2020. https://doi.org/10.6084/m9.figshare.11831343.v3

5. Renna JNL, Silva GA. Temporal trend and associated factors to advanced stage at diagnosis of cervical cancer: Analysis of data from hospital based cancer registries in Brazil, 2010-2012. Epidemiol Serv Saude 2018, 27(2);e2017285.

https://doi.org/10.5123/S1679-49742018000200003

6. Teston EF, Fukumori EFC, Beneditti GMS, Spigolon DN, Costa MAR, Marcon SS. Feelings and difficulties experienced by cancer patients along the diagnostic and therapeutic itineraries. Escola Anna Nery 2018;22(4):e20180017. https://doi.org/10.1590/2177-9465-ean-2018-0017

7. Goldman RE, Figueiredo EN, Fustinoni SM, Souza KMJ, Almeida AM, Gutiérrez MGR. Brazilian breast cancer care network: The perspective of health managers. Rev Bras Enferm 2019; 72(suppl 1):274-281. https://doi.org/10.1590/0034-7167-2017-0479

8. Singer SJ, Burgers J, Friedberg M, Rosenthal MB, Leape L, Schneider E. Defining and Measuring Integrated Patient Care: Promoting the Next Frontier in Health Care Delivery. Med Care Res Rev 2011;68(1):112-27. https://doi.org/10.1177/1077558710371485

9. Wakiuchi J, Marcon SS, Oliveira DC, Sales CA. Chemotherapy under the perspective of the person with cancer: a structural analysis. Texto \& Contexto - Enfermagem 2019; 28:e20180025. https://doi.org/10.1590/1980-265x-tce-2018-0025 
10.Fowler H, Belot A, Ellis L, Maringe C, Luque-Fernandez MA, Njagi EN, et al. Comorbidity prevalence among cancer patients: a population-based cohort study of four cancers. BMC Cancer 2020;20(1):2. https://doi.org/10.1186/s12885-019-6472-9

11.DusekB,PearceN,HarripaulA,LloydM.Caretransitions:Asystematic reviewofbestpractices. J Nurs Care Qual 2015;30(3):233-239. https://doi.org/10.1097/NCQ.0000000000000097

12.Registered Nurses' Association of Ontario. Care transitions [RNAO]. Clinical Best Practice Guidelines. 2014. https://rnao.ca/sites/rnao-ca/files/Care_Transitions_BPG.pdf

13.Baxter R., O'Hara J, Murray J, Sheard L, Cracknell A, Foy R, et al. Partners at care transitions: Exploring healthcare professionals' perspectives of excellence at care transitions for older people. BMJ Open 2018;8(9):e022468. https://doi.org/10.1136/bmjopen-2018-022468

14.Facchinetti G, D’Angelo D, Piredda M, Petitti T, Matarese M, Oliveti A. Continuity of care interventions for preventing hospital readmission of older people with chronic diseases: $A$ meta-analysis.IntJNursStud 2020;101:103396. https://doi.org/10.1016/j.ijnurstu.2019.103396

15.Coleman EA, Boult C, American Geriatrics Society Health Care Systems Committee. Improving the quality of transitional care for persons with complex care needs. $J$ Am Geriatr Soc 2003;51(4):556-557. https://doi.org/10.1046/j.1532-5415.2003.51186.x

16.Lima MADS, Magalhães AMM, Oelke ND, Marques GQ, Lorenzini E, Weber LAF, Fan I. Care transition strategies in Latin American countries: an integrative review. Rev Gaucha Enferm 2018;39:e20180119. https://doi.org/10.1590/1983-1447.2018.20180119

17.Rohsig V, Silva P, Teixeira R, Lorenzini E, Maestri R, Saraiva T, Souza A. Nurse navigation program: Outcomes from a breast cancer center in Brazil. Clin J Oncol Nurs 2019;23(1):E25-E31. https://doi.org/10.1188/19.CJON.E25-E31

18.Durcinoska I, Young JM, Solomon MJ. Patterns and predictors of colorectal cancer care coordination: A population-based survey of Australian patients. Cancer 2017;123(2):319-326. https://doi.org/10.1002/cncr.30326

19.Conn LG, Mobilio MH, Rotstein OD, Blacker S. Cancer patient experience with navigation service in an urban hospital setting: a qualitative study. Eur J Cancer Care (Engl) 2016;25(1):132140. https://doi.org/10.1111/ecc.12247

20.Borenstein M, Hedges LV, Higgins JP, Rothstein HR. A basic introduction to fixed-effect and random-effects models for meta-analysis. Res Synth Methods 2010;1(2):97-111. https://doi.org/10.1002/jrsm.12

21.Moher D, Shamseer L, Clarke M, Ghersi D, Liberati A, Petticrew M, et al. Preferred reporting items for systematic review and meta-analysis protocols (PRISMA-P) 2015 statement. Syst Rev 2015;4(1):1. https://doi.org/10.1186/2046-4053-4-1

22.Shah PM, Johnston L, Sarosiek B, Harrigan A, Friel CM, Thiele RH, et al. Reducing Readmissions While Shortening Length of Stay: The Positive Impact of an Enhanced Recovery Protocol in Colorectal Surgery. Dis Colon Rectum. 2017;60(2):219-227.

https://doi.org/10.1097/DCR.0000000000000748

23.Viana LRC, Pimenta CJL, Ferreira GRS, Oliveira JS, Costa TF, Costa KNFM. Health-related quality of life and therapeutic adherence in breast and prostate cancer. Texto Contexto Enferm. 2021;30:e20200217. https://doi.org/10.1590/1980-265X-TCE-2020-0217

24.Borsuk DJ, Al-Khamis A, Geiser AJ, Zhou D, Warner C, Kochar K, et al. S128: Active post discharge surveillance program as a part of Enhanced Recovery After Surgery protocol decreases emergency department visits and readmissions in colorectal patients. Surg Endosc. 2019;33(11):3816-3827. https://doi.org/10.1007/s00464-019-06725-x

25.Goldenberg BA, Carpenter-Kellett T, Gingerich JR, Nugent Z, Sisler JJ. Moving forward after cancer: successful implementation of a colorectal cancer patient-centered transitions program. J Cancer Surviv. 2020;14(1):4-8. https://doi.org/10.1007/s11764-019-00819-0 
26.Alavi M, Hunt GE, Visentin DC, Watson R, Thapa DK, Cleary M. Using risk and odds ratios to assess effect size for meta-analysis outcome measures. J Adv Nurs 2020;76(12):3231-3234. https://doi.org/10.1111/jan.14528

27.Silva TTM, Araújo NM, Sarmento SDG, Castro GL, Dantas DV, Dantas RAN. Impact of COVID-19in patientswith cancer:a scoping review.TextoContextoEnferm.2021;30:e20200415. https://doi.org/10.1590/1980-265X-TCE-2020-0415 